\title{
Review of: Dabbagh, N., Marra, R. M., \& Howland, J. L., (2018). Meaningful online learning: Integrating strategies, activities, and learning technologies for effective designs. Routledge.
}

\author{
Cecil R. Short ${ }^{1} \cdot$ Charles R. Graham ${ }^{1}$ \\ Accepted: 1 October 2020 / Published online: 8 October 2020 \\ (C) Association for Educational Communications \& Technology 2020
}

\section{Introduction}

Trends suggest that online learning and training continues to be on the rise in $\mathrm{K}-12$, higher education, corporate, and government settings (Allen and Seaman 2016; Evergreen Education Group 2015; Vernau and Hauptmann 2014). Such a rise has become even more prevalent due to the COVID-19 pandemic (Hartshorne et al. 2020). With designers, teachers, and trainers moving from in-person teaching to online teaching, many are seeking ways to make sure that online learning courses and training modules provide deep meaningful learning experiences and do not simply become a way to transmit and store information - enter Dabbagh et al. (2018) Meaningful Online Learning: Integrating Strategies, Activities, and Learning Technologies for Effective Designs.

The book uses a design framework that starts with the goal of meaningful learning outcomes to provide practitioners with theories, strategies, and tools to create meaningful online learning (MOL). The book takes a bold approach in selecting such a broad audience. It seeks to provide insights into MOL for K-12 teachers, college and university faculty who may act as designers of online learning, as well as insights for instructional designers working in private, corporate, or governmental contexts. This is a wide array of audiences as online learning will certainly look different in each of these contexts; however, the authors are able to provide examples of theories, practices, and tools that either span all contexts, or that have principles that can be easily extrapolated and applied across all online learning and training contexts. For this reason, this

Charles R. Graham

charles.graham@byu.edu

Cecil R. Short

cecil.r.short@gmail.com

1 Brigham Young University, Provo, UT, USA book is a good resource for those seeking to better understand how to make online learning a meaningful experience for their learners.

\section{Frameworks and Organization}

The preface to Meaningful Online Learning introduces two key frameworks that are used throughout the book as reference points and to provide the book's organizational structure. The first of these frameworks is the authors' Meaningful Online Learning design framework. The framework helps to define meaningful learning as learning that is (a) active, (b) constructive, (c) cooperative, (d) authentic, and (e) intentional, while also providing an explanation as to how these characteristics relate to online learning technologies, instructional strategies, and learning activities. The second framework, "Technology Categories for Meaningful Online Learning," provides six categories of learning technology tools used in meaningful online learning: (1) collaboration and communications tools, (2) content creation tools, (3) information search and resource management tools, (4) knowledge representation tools, (5) immersive tools, and (6) assessment and analytics tools.

In order to cover MOL theoretical, pedagogical, and technological constructs across the learning and training contexts mentioned above, the book is thematically organized into eight chapters. The first chapter further details the MOL design framework, describing each of its constructs. The second chapter lays the foundation for the following five chapters by providing a pedagogical model for online learning. Chapters 3 and 4 each focus on two aspects of this model - instructional strategies, and learning technologies, respectively. Chapters 5 through 7 detail the final characteristic of the pedagogical model, each respectively focusing on various MOL instructional strategies - supportive strategies, dialogic strategies, 
and exploratory strategies - by describing valuable practices and technologies for each practice category. The final chapter details the creation of assessments that meet the goals of learning that is both online and meaningful.

\section{Content Overview}

The first chapter of Meaningful Online Learning sets up the goals and focus of the book. The main sections of the chapter focus on online learning, meaningful learning, and then designing for meaningful online learning. The online learning section details what online learning looks like in the various education/training contexts used throughout the book - higher education, K-12, corporate, government, and healthcare. These last two contexts are assimilated into the other contexts later, as the "Standards for Designing Meaningful Online Learning Environments" section only includes higher education, K-12, and corporate education in its descriptions. The section on meaningful learning sets meaningful learning apart from other learning or training by detailing meaningful learning's five characteristics.

In Chapter 2, the authors use pedagogical ecology - the idea that each learning context has a unique set of factors that contribute to learning in that setting, and that altering any one of these factors has the potential to disrupt others - to introduce the Three-Component Pedagogical Model for Online Learning. This model consists of instructional strategies, learning technologies, and learning activities. The authors relate it to the MOL design framework to set up the next 5 chapters.

Chapters 3 and 4 each focus on one aspect of Chapter 2's pedagogical model. Chapter 3 uses backwards design to explain how instructors/teachers/designers should choose the instructional strategies that they use. Such instructional strategies are divided into three categories - supportive strategies, dialogic strategies, and exploratory strategies. Each of these categories is broken down into specific strategies and the authors provide descriptions for how each strategy can be used to promote MOL. Chapter 4 uses the "Technology Categories for Meaningful Online Learning" from the preface to categorize and detail various learning technologies and their affordances and significance to MOL.

Chapters 5, 6, and 7 take the technologies from Chapter 4 and combine them with instructional strategies from Chapter 3 to provide specific learning activities that can be used to create MOL. In putting all the characteristics from the Online Pedagogical Model together, Chapters 5 through 7 are where this book really shines. Each chapter's example practices and lists of technologies are invaluable in understanding how to create and facilitate MOL. Readers not only walk away from these chapters with a lot of learning activity ideas, but a long list of technologies to use in enacting such ideas.
Chapter 5 details supportive instructional strategies including scaffolding, modeling, and coaching/mentoring and explains how the primary technology category used to facilitate these methods is Content Creation Tools and that Knowledge Representation Tools can also be useful. Chapter 6 details dialogic instructional strategies including articulation, collaboration, and reflection and explains how the primary technology category used to facilitate these methods is Collaboration and Communication Tools, as well as Knowledge Representation Tools and Search and Resource Management Tools. Chapter 7 details exploratory instructional strategies including problem representation, and hypothesis testing and explains how the technology categories of Knowledge Representation Tools, Information Resource and Knowledge Management Tools, and Immersive Tools can be used to facilitate these methods.

The final chapter of the book revisits an aspect of backwards design that the authors had not yet given a detailed focus - assessment. Chapter 8 details the purposes of assessment in both educational and training contexts, the tools needed to make sure those purposes are fulfilled, the creation of well-designed rubrics for assessing meaningful online learning, and the role learning analytics can play throughout instructional processes. The chapter stresses the importance of feedback to MOL, and how assessment's primary purpose should be to provide such feedback.

\section{Conclusion}

Overall, Dabbagh et al. (2018) Meaningful Online Learning: Integrating Strategies, Activities, and Learning Technologies for Effective Designs provides an extensive look at layering meaningful learning onto online learning. While some of the book's target audience may get bogged down in the theory and theoretical frameworks of the early chapters, the diagrams and graphics provided for each theory clarify complex ideas and make such theories easier to understand. The real benefit of the book comes in the later chapters that bring theories, practices, and technologies together to provide examples of meaningful online learning across various learning and training contexts. As such, this book is a good resource for designers and instructors seeking to enhance online learning in ways that make such learning more meaningful.

\section{References}

Allen, I., \& Seaman, J. (2016). Online report card tracking online education in the United States. Babson Survey Research Group and Quahog Research Group, LLC. 
Dabbagh, N., Marra, R. M., \& Howland, J. L. (2018). Meaningful online learning: Integrating strategies, activities, and learning technologies for effective designs. Routledge.

Evergreen Education Group (2015). Keeping pace with K-12 digital learning. www.kpk12.com/wp-content/uploads/Evergreen KeepingPace_2015.pdf

Hartshorne, R., Baumgartner, E., Kaplan-Rakowski, R., Mouza, C., \& Ferdig, R. E. (2020). Special issue editorial: Preservice and inservice professional development during the COVID-19 pandemic. Journal of Technology and Teacher Education, 28(2), 137-147.
Vernau, K., \& Hauptmann, M. (2014). Corporate learning goes digital: How companies can benefit from online education. Roland Berger Strategy Consultants GMBH. www.rolandberger.com/media/ publications/2014-06-02-rbsc-pub-Corporate_learning_goes_ digital.html

Publisher's Note Springer Nature remains neutral with regard to jurisdictional claims in published maps and institutional affiliations. 